\title{
Determination of Mining-Induced Changes in Hydrogeological Parameters of Overburden Aquifer in a Coalfield, Northwest China: Approaches Using the Water Level Response to Earth Tides
}

\author{
Qingyu Xu $\mathbb{D},,^{1,2}$ Guangcai Wang $\mathbb{D}^{1,2}$ Xiangyang Liang, ${ }^{3}$ Shen $Q u,{ }^{1,2}$ Zheming Shi, ${ }^{1,2}$ \\ and Xianbin Wang ${ }^{1,2}$ \\ ${ }^{1}$ State Key Laboratory of Biogeology and Environmental Geology \& MOE Key Laboratory of Groundwater Circulation and \\ Environment Evolution, China University of Geosciences, Beijing 100083, China \\ ${ }^{2}$ School of Water Resources and Environment, China University of Geosciences, Beijing 100083, China \\ ${ }^{3} X i$ 'an Research Institute of China Coal Technology \& Engineering Group, Xi'an 710077, China
}

Correspondence should be addressed to Guangcai Wang; wanggc@pku.edu.cn

Received 2 March 2021; Revised 26 April 2021; Accepted 15 May 2021; Published 24 May 2021

Academic Editor: Yi Xue

Copyright (c) 2021 Qingyu Xu et al. This is an open access article distributed under the Creative Commons Attribution License, which permits unrestricted use, distribution, and reproduction in any medium, provided the original work is properly cited.

\begin{abstract}
The determination of changes in hydrogeological properties (e.g., permeability and specific storage) of aquifers disturbed by mining activity is significant to groundwater resource and ecological environment protection in coal mine areas. However, such parameters are difficult to continuously measure in situ using conventional hydrogeological methods, and their temporal changes associated with coal mining are not well understood. The response of well water level to Earth tides provides a unique probe to determine the in situ hydrogeological parameters and their variations. In this study, the tidal responses of well water level were employed to characterize the changes in hydrogeological parameters of the overburden aquifer induced by longwall mining in a coalfield, northwest China. Based on the long-term hourly recorded water level data, two analytical models were used to determine the temporal changes of permeability and specific storage of the overburden aquifer. The results showed that the hydrogeological parameters changed with the longwall coal face advance. When the longwall coal face approached the wells, the aquifer permeability increased several to dozens of times, and the response distance ranged from $80 \mathrm{~m}$ to $300 \mathrm{~m}$. The specific storage decreased before the coal face reached wells and recovered after the coal face passed. The results of this study indicate that the hydrogeological parameter changes induced by coal mining are related to the location of the well relative to the coal face and the stress distribution in the overburden aquifer. This study revealed the changes in permeability and specific storage associated with the mining disturbance which could have great significance for quantitative assessment of the impact of mining on overburden aquifer.
\end{abstract}

\section{Introduction}

Underground coal mining could change the structure and properties of the overburden aquifers due to surrounding rock stress changes and cause deformation which results in subsidence or settlement of the ground surface. The slight changes of stress and strain in the rock mass can be reflected in the change of pore pressure or well water level through seepage flow or the transfer of hydrostatic pressure [1]. Furthermore, high-intensity groundwater pumping and draining as well as strong mining vibration during the mining processes may cause the clogging or unclogging of fissures/fractures in aquifers and the resultant hydrogeological property changes. Therefore, the hydrogeological parameters (e.g., permeability and specific storage) can be used as an indicator of the deformation of the aquifer associated with mining activities.

Groundwater flow in the overburden aquifer during longwall mining is governed by a complex interaction between roof caving and ground subsidence, pore pressure, and permeability changes and is influenced by in situ geological and hydrogeological conditions [2]. The parameter 
variations of the overlying aquifer during longwall mining have been studied by many researchers. During mining, the rock failure above a longwall coal face may increase the aquifer permeability $[3,4]$. After mining, the permeability in the fractured zone may decrease due to stress reestablishment and fracture closure $[5,6]$. The aquifer permeability and specific storage could be varied up to two or three orders of magnitude due to mining [7]. However, temporal changes in hydrogeological properties are still not well characterized and understood because it is difficult to evaluate the continuous variation of aquifer parameters due to the lack of corresponding methods. Generally, numerical modeling $[4,8,9]$ and laboratory and in situ experiments [10-12] are utilized to evaluate the parameter variations of the overlying aquifer during mining. However, numerical modeling usually needs a lot of observation and experimental data and needs to simplify the boundary conditions and formation structures, which could cause uncertainty of the results. The laboratory and in situ experiments, such as the pumping test, are expensive, time-consuming, and not suitable for long-term continuous observation. As a result, we need an in situ, convenient, and inexpensive way to obtain continuous hydrogeological parameters during mining activity. The methods based on the tidal response of the well water level provide a plausible way to such requirements.

The theoretical development on the response of wellaquifer systems to Earth tidal loading has been well documented since the 1960s [13-16]. It has been known that the well water level in a well-confined aquifer can be a good measure of the crustal solid tide strain [17]. The water level in a well fluctuates in response to pressure head variations caused by the dilation of the aquifer under the Earth tidal loading [14]. Because time is needed for water to flow into or out of the well, there exists a phase shift between the tidal dilation of the aquifer and the water level response in the well. The amplitude and phase shift of the well water level to Earth tides are the functions of aquifer transmissivity, storage coefficient, and the period of the harmonic disturbance $[18,19]$. Therefore, tidal response of well water level can be used to determine aquifer parameters such as permeability and specific storage. On the basis of the theory, two well-known classical models, the vertical flow model and horizontal flow model, were proposed $[18,19]$. This method provides a way to determine the in situ hydrogeological parameters and has been used in some research fields such as aquifer deformations induced by earthquakes [20-23]. However, only a few studies have investigated the strain changes and fracture development under continuous mining disturbance using the tidal response of well water level, which may be different from the earthquake-induced changes that are mainly caused by transient stresses. The temporal changes of the hydrogeological parameters associated with coal mining are still not well understood.

To study the changes in hydrogeological parameters of aquifer disturbed by mining activity, we observed the tidal response of well water level in three wells in Ningtiaota Coalfield, northwest China. The spectral and tidal analyses were applied to identify and extract the tidal components in the well water level. The permeability and specific storage were estimated by two models (vertical flow model and horizontal flow model). The variation characteristics of permeability and specific storage associated with the process of coal face advancing were also investigated.

\section{Study Area}

The Ningtiaota Coalfield is located in the northern Shaanxi Province, northwest China (Figure 1). The regional stratum was generally characterized by a monoclinic layer that was gently inclined to the northwest, with a dip angle of about 1 degree. The stratum sequences from top to bottom are the Quaternary Holocene alluvium $\left(\mathrm{Q}_{4}{ }^{\mathrm{al}}\right)$ and eolian sand $\left(\mathrm{Q}_{4}{ }^{\mathrm{eol}}\right)$, the Upper Pleistocene Salawusu Group $\left(\mathrm{Q}_{3} \mathrm{~s}\right)$, the Middle Pleistocene Lishi Group $\left(\mathrm{Q}_{2} \mathrm{l}\right)$, the Neogene Pliocene Baode Group $\left(\mathrm{N}_{2} \mathrm{~b}\right)$, the Middle Jurassic Zhiluo Group $\left(\mathrm{J}_{2} \mathrm{z}\right)$, and the Yan'an Group $\left(\mathrm{J}_{2} \mathrm{y}\right)$ (Table 1$)$. So far, according to the geological investigation, mine construction, and production, no faults or folds were found in this area.

A coal seam is located at the top of the fourth section of the Yan'an Group, and the coal-bearing sequences extend approximately horizontally. The thickness of the overburden layers of the excavated coal seams varies from $2 \mathrm{~m}$ to $247 \mathrm{~m}$. Aquifers were classified according to drill core logging and pumping tests. In the light of lithology, the top Quaternary strata $\mathrm{Q}_{3} \mathrm{~s}, \mathrm{Q}_{4}{ }^{\mathrm{eol}}$, and $\mathrm{Q}_{4}{ }^{\mathrm{al}}$ comprise fine-grained sand, sandy soil, and sandy clay, which are considered unconfined aquifers. The Lishi Group $\left(\mathrm{Q}_{2} \mathrm{l}\right)$ and Baode Group $\left(\mathrm{N}_{2} \mathrm{~b}\right)$ are characterized as sandy clay and clay, which are considered an aquitard. The direct overburden aquifer of the coal-bearing sequence is the Jurassic Zhiluo Group $\left(\mathrm{J}_{2} \mathrm{z}\right)$ fractured aquifer, with well-developed weathered medium-coarse-grained gravel-bearing sandstone. The source of water in the underground tunnel was found to be mainly from this aquifer during coal mining. Compared with the Yan'an Group $\left(\mathrm{J}_{2} \mathrm{y}\right)$, a more intense weathering process has occurred in the Zhiluo Group $\left(\mathrm{J}_{2} \mathrm{z}\right)$. Although similar in lithology, they are quite different in structures. We could also obtain the same aquifer classification from the pumping test. As shown in Table 1, the values of aquifer parameters of the Yan'an Group $\left(\mathrm{J}_{2} \mathrm{y}\right)$ are much smaller than those of the Zhiluo Group $\left(\mathrm{J}_{2} \mathrm{z}\right)$. Furthermore, there are weak hydraulic connections between Quaternary and Jurassic aquifers [24].

The S1229 coal face is about $4 \mathrm{~km}$ in length, $260 \mathrm{~m}$ in width, and with a mining height of around $5.7 \mathrm{~m}$. The S1229 coal face is located in the middle of the coalfield, and several coal faces in the north had already been excavated. The S1229 coal face excavation started in September 2015 in a westward direction (Figure 2(a)) and ended in September 2017. During this period, the total water inflow in the underground tunnel is observed (Figure 2(b)).

\section{Observations}

Three wells (J7, J10, and J14) are used to monitor the water level from the start of mining of the S1229 coal face in September 2015 through September 2017. J7 is located directly above the S1229 coal face. J10 is about 122 meters away from the south side of the S1229 coal face. J14 is chosen as the comparable well because it is far away from the S1229 coal 


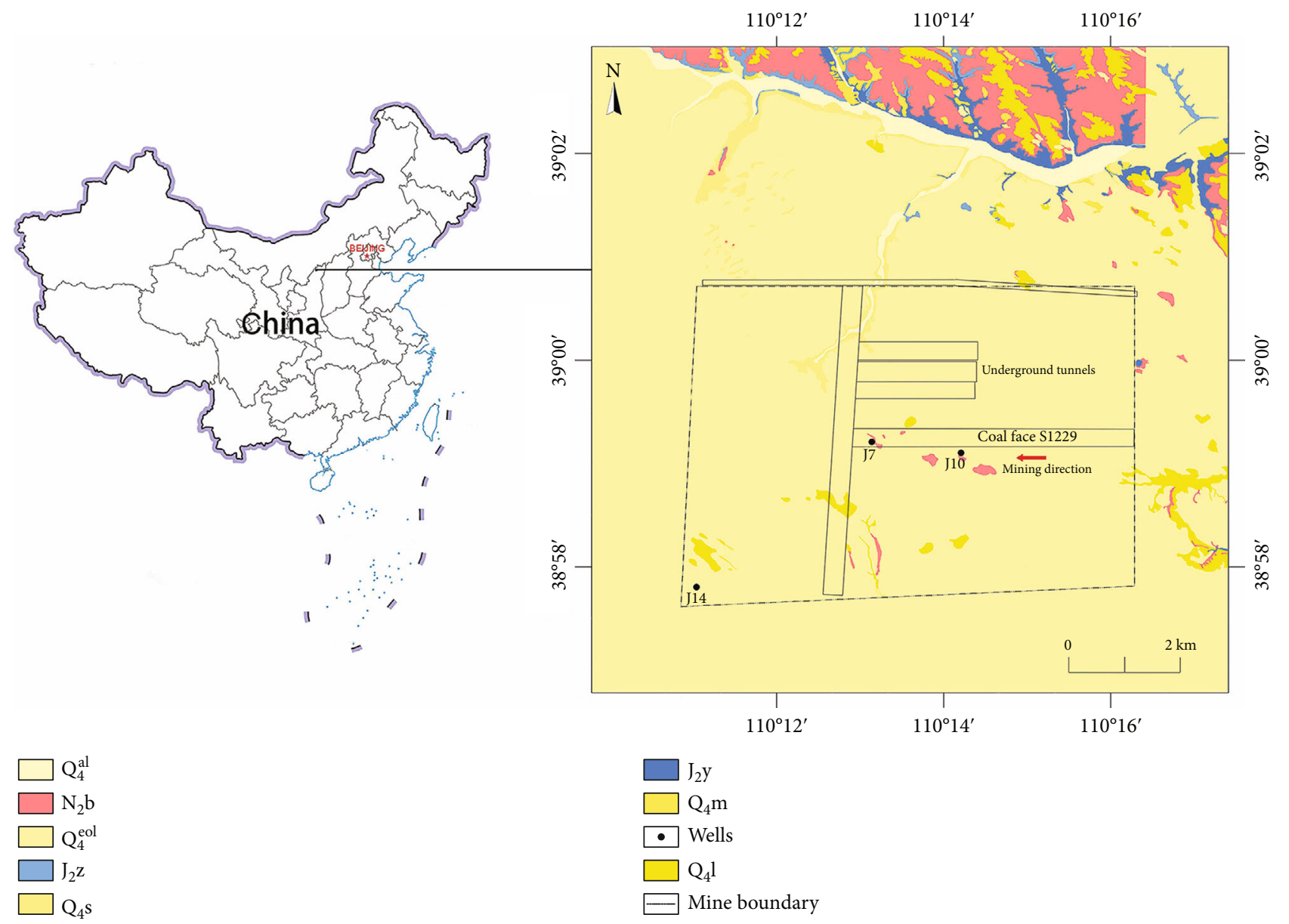

Figure 1: Geological map with location of longwall coal faces, boreholes of Ningtiaota Coalfield.

face and least affected by mining activity. Information on well structures is shown in Figure 3 and detailed in Table 2. All of the wells were instrumented with pressure sensors (levelogger) to measure the height of the water column above the sensors with the sampling frequency of one hour. The accuracy of the pressure sensors is $\pm 0.05 \%$ of the full scale for sensors with a range of $100 \mathrm{ft}$ and a resolution of 24 bits of the same scale. To evaluate the effects of the barometric pressure, a pressure transducer (barologger) was also set up in the air inside well J7. Besides, rainfall data are obtained from the weather station we installed in the mining district. Figure 4 shows the observations of the water level and barometric and precipitation data during S1229 coal face excavation. The sensor in J7 was taken out for about one week in April 2017, so there was no recorded water level data during this period. Otherwise, all the data is continuous.

As shown in Figure 4, the water level in J7 declined gradually since the start of mining. From the start of mining to June 2017, the water level in J7 declined $4 \mathrm{~m}$ gradually; by this time, the longwall excavation zone was about $300 \mathrm{~m}$ away from J7. In March 2017, the J7 water level appeared two abnormal fluctuations. The water level dropped rapidly from June 2017; the water level had dropped $42 \mathrm{~m}$ when mining reached the position beneath the $\mathrm{J7}$ well in the middle of August. Because of the rapid decrease of the water level, the sensor was exposed to the air and failed to record data on August 16. Two days later, the water level rose steadily, and then, an instantaneous decrease was observed on August 25. Unfortunately, 15 days after the S1229 coal face passed the J7 well, the borehole was damaged and subsequent water level data was missing.

The water level variations are different in J10 compared with those of J7. One noticeable difference is that the water level in J10 started declining rapidly when the longwall excavation zone was approximately $200 \mathrm{~m}$ away in February 2017, and then, the water level kept falling until the $\$ 1229$ coal face excavation ended.

The water levels in J7 and J10 varied greatly, while there is no distinct change in the water level in J14. Besides, there were no significant water level changes with the rainfall. Combining Figure 2 with Figure 4, it is obvious that the dramatic changes in the water level of J7 and J10 are related to the mining of the $S 1229$ coal face.

\section{Methods}

The variation of aquifer parameters in coal mining areas mainly results from the disturbance of geological media caused by mining activities and mine drainage. This variation can be directly reflected in the water level. Based on the 


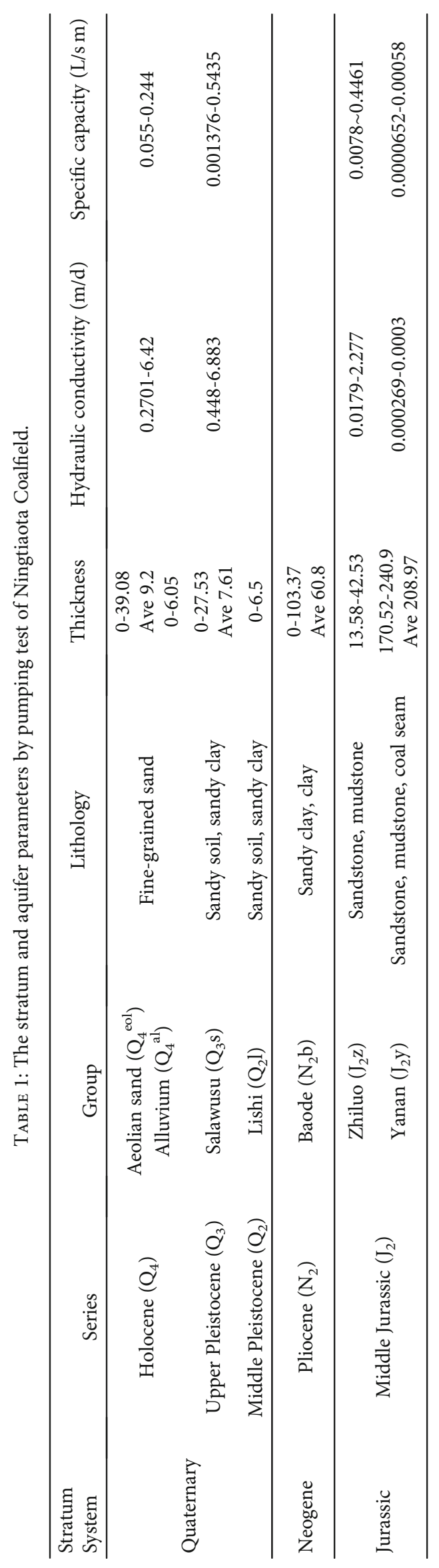




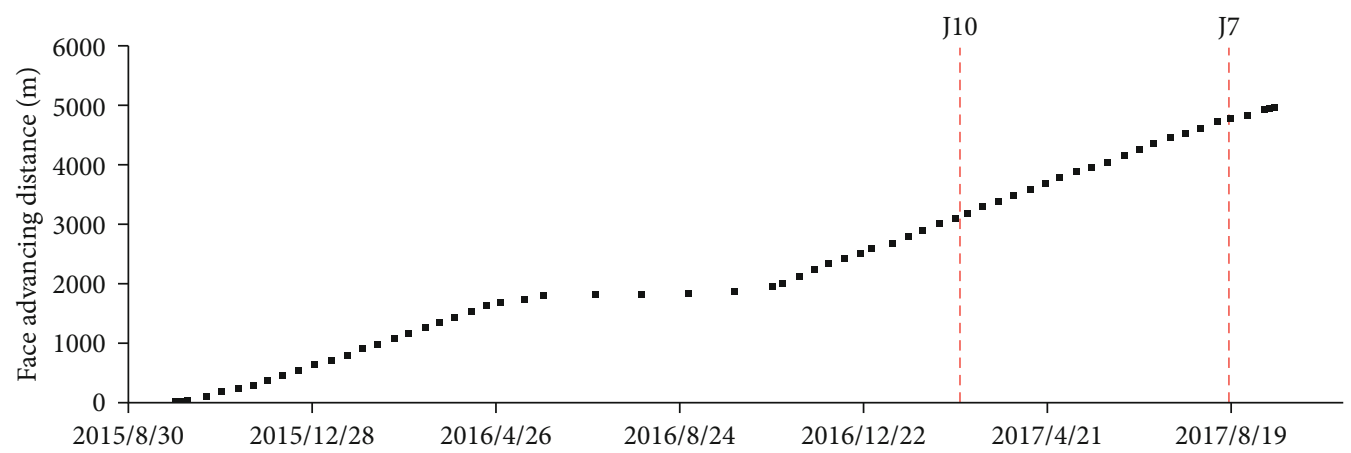

(a)

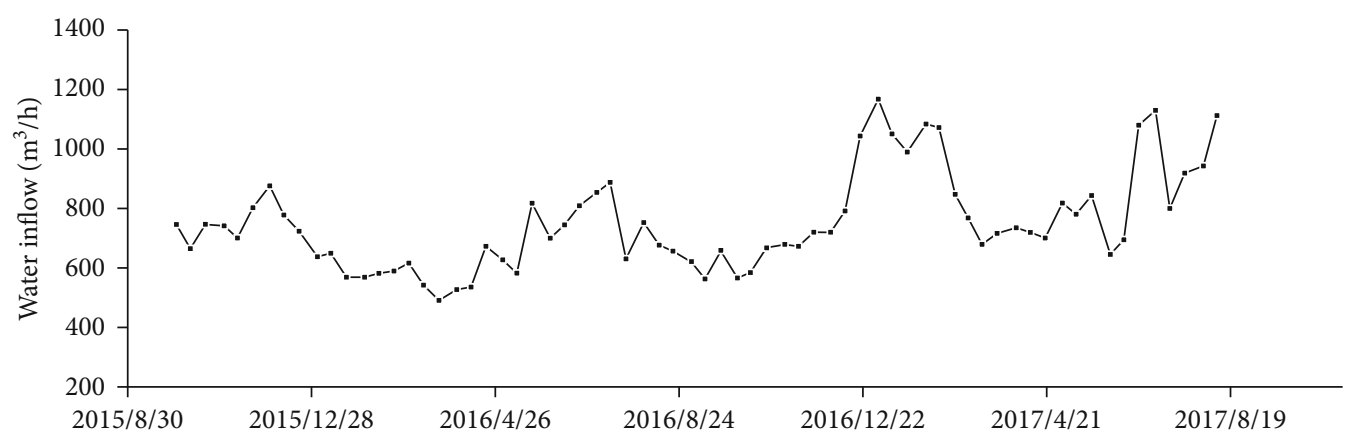

(b)

FIGURE 2: (a) S1229 panel advancing distance and (b) water inflow of entire coalfield. Red vertical dash lines show the times when the longwall excavation zone is closest to the J10 and J7 wells, respectively.

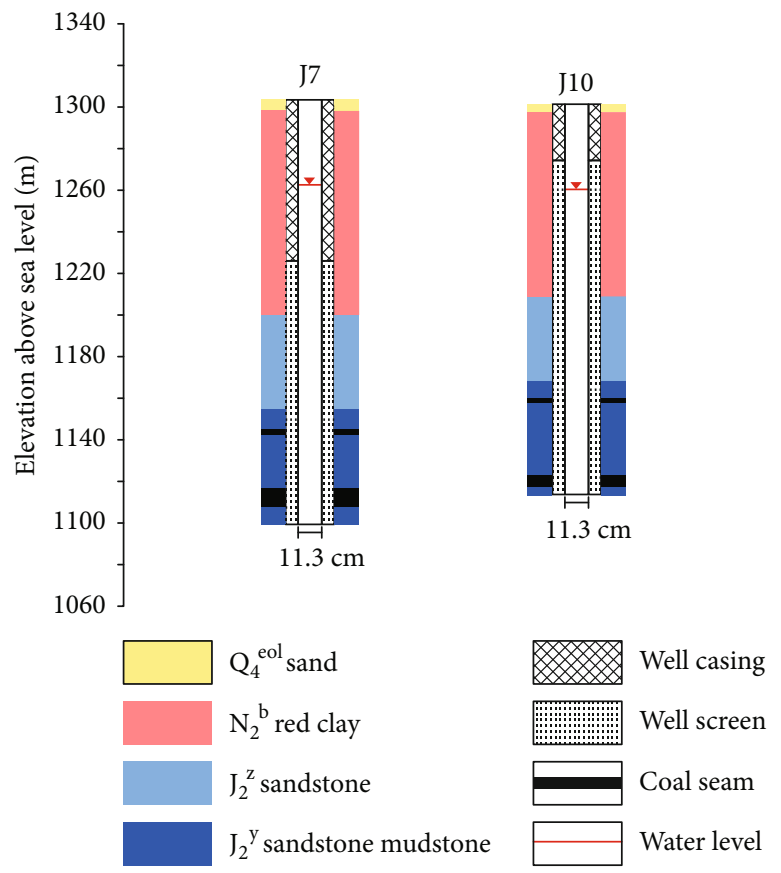

FIGURE 3: Well construction information.

continuous time series of water levels, we extract the solid tide component in the well water level by tidal analysis, and then, we utilize two analytical models to calculate the aquifer parameters.
4.1. Spectral and Tidal Analysis. First, we conducted a spectral analysis to identify the tidal components based on the water level data at three wells and local barometric pressure data, in which a band-pass filter of 0.8 to 2.2 cycles/day was 
TABLE 2: Monitored wells in mining areas.

\begin{tabular}{lcccccc}
\hline Well & Radius $(\mathrm{cm})$ & Total depth $(\mathrm{m})$ & Casing depth $(\mathrm{m})$ & Coal seam depth $(\mathrm{m})$ & Surface elevation $(\mathrm{m})$ & Distance from startup $(\mathrm{m})$ \\
\hline $\mathrm{J} 7$ & 11.3 & 203.3 & 78.0 & 185.5 & 1310.2 & 4755 \\
$\mathrm{~J} 10$ & 11.3 & 171.1 & 30.0 & 141.0 & 1309.7 & 3162 \\
$\mathrm{~J} 14$ & 11.3 & 188.4 & 72.0 & 174.2 & 1283.5 & 8368 \\
\hline
\end{tabular}

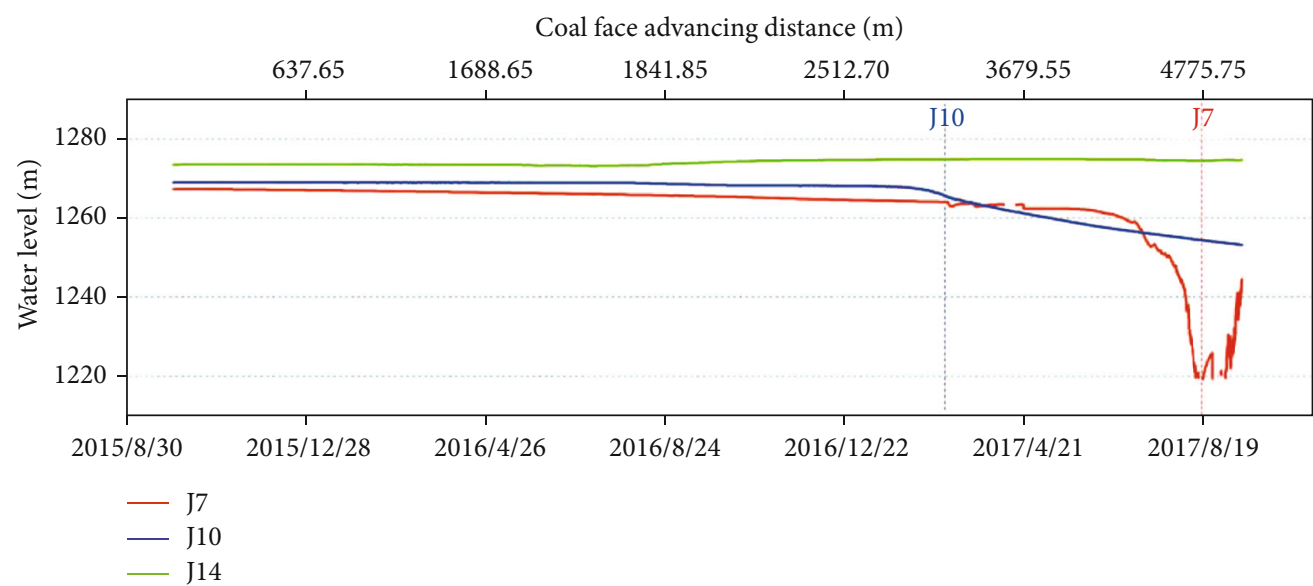

(a)

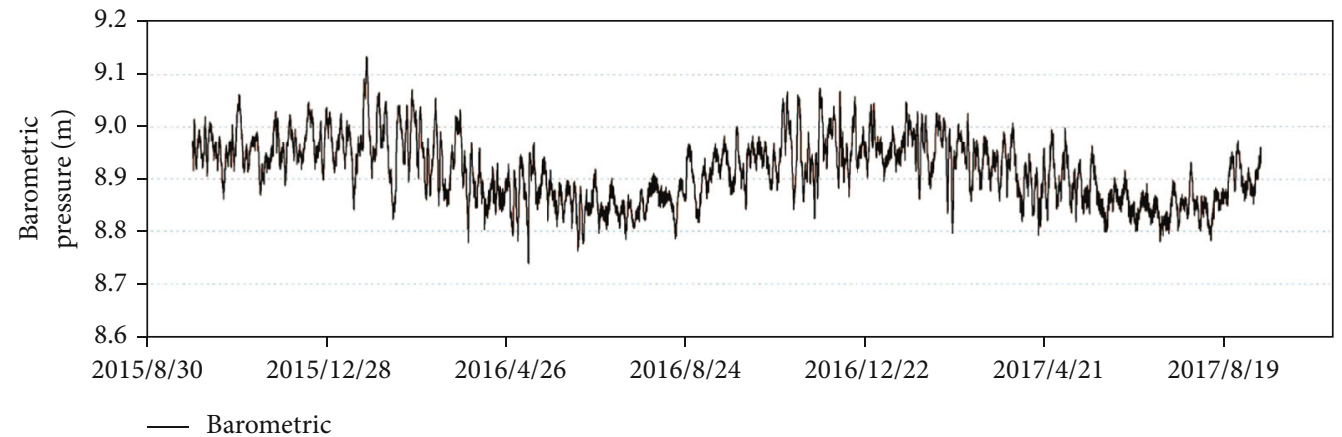

(b)

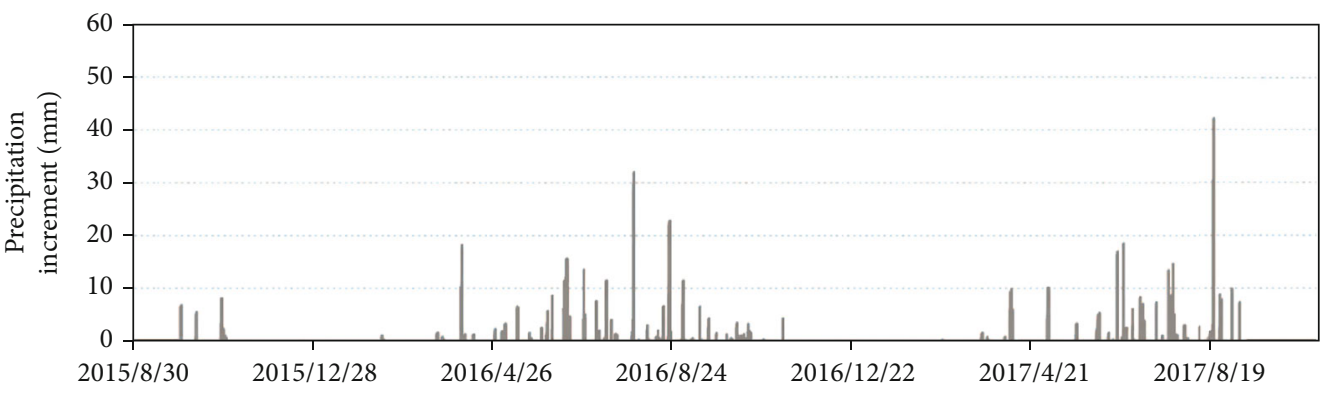

(c)

FIgURE 4: The observed hourly spaced record for (a) water levels, (b) barometric pressures, and (c) rainfall. The blue and red vertical dash lines show the times when the longwall excavation zone is closest to the J10 and J7 wells, respectively. The coal face advancing distance is the distance from the coal face startup.

used to eliminate the long-term trend of the water level data and the high-frequency noise. Although there may be dozens of tidal constituents that can be analyzed, the main lines of the spectrum of the tidal potential are due to the $\mathrm{O} 1, \mathrm{~K} 1, \mathrm{M} 2, \mathrm{~S} 2$, and $\mathrm{N} 2$ tides [18]. The N2 constituent was neglected due to its small amplitude. Therefore, we used four tidal constituents, O1, K1, M2, and S2, in the frequency domain analysis. Then, a program Baytap 08 is used to measure the phase and amplitude responses of water level for each tidal constituent and the corresponding errors. We also set local barometric pressure as an auxiliary series to eliminate the effect of barometric pressure on the water level. The study site is far from the ocean, so the ocean tide is ignored. 


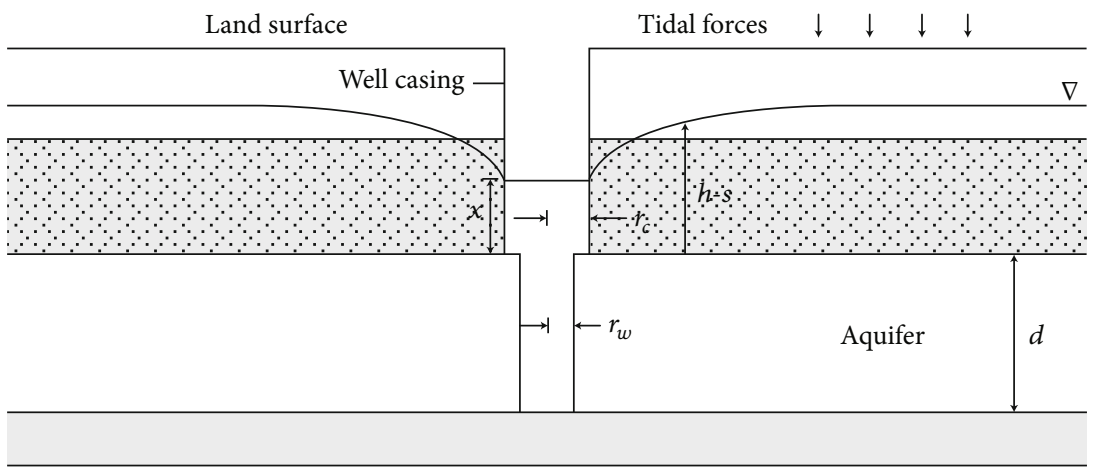

Figure 5: Illustration of an idealized well in a confined aquifer. Note: $r_{c}$ is the inner radius of the casing. $r_{w}$ is the screened portion of the well. $s$ is the drawdown of the pressure head. $d$ is the aquifer thickness.

4.2. Analytical Model. Figure 5 shows an idealized well in a confined aquifer. We assumed that the aquifer is twodimensional isotropic, homogenous, and laterally extensive. The water level $(x)$ in the well fluctuates in response to pressure head $(h)$ variations caused by the dilation of the aquifer under the tidal forces. The amplitude and phase lag of well water level are the functions of the inner radius of the casing $\left(r_{c}\right)$, radius of the screened portion of the well $\left(r_{w}\right)$, aquifer transmissivity, and storage coefficient $[18,19]$. Two analytical models determining the functional relationships, i.e., horizontal flow model and vertical flow model, were developed and have been widely used $[18,19]$. We used a horizontal flow model, in which the flow to the well is radial, to determine the aquifer parameters [18]. However, the observed phase shift of J10 and J14 is positive, which may be caused by leakage to the water table [19] and cannot be described by a horizontal flow model. As a result, we need a vertical flow model applied to J10 and J14. Therefore, we use a horizontal flow model to calculate the hydrogeological parameters for the J7 well and use a vertical flow model to calculate the hydrogeological parameters for the other wells.

4.2.1. Horizontal Flow Model. As mentioned above, in a wellconfined aquifer, both the phase lag and amplitude of well water level are the function of transmissivity and storage coefficient of aquifer [18]. Therefore, we can calculate the permeability and specific storage according to the phase shift and amplitude response. Analysis was based on the analytical solution proposed by Hsieh et al. [18]; the amplitude response $A$ and phase shift $\eta$ can be represented as

$$
\begin{gathered}
A=\left|\frac{x_{0}}{h_{0}}\right|=\left(E^{2}+^{2}\right)^{-1 / 2}, \\
\eta=\arg \left(\frac{x_{0}}{h_{0}}\right)=-\tan ^{-1}\left(\frac{F}{E}\right),
\end{gathered}
$$

where

$$
E \approx 1-\frac{\omega r_{c}^{2}}{2 T} \operatorname{Kei}\left(\alpha_{w}\right)
$$

$$
\begin{gathered}
F \approx \frac{\omega r_{c}^{2}}{2 T} \operatorname{Ker}\left(\alpha_{w}\right), \\
\alpha_{w}=\left(\frac{\omega S}{T}\right)^{1 / 2} r_{w}, \\
S=S_{s} d .
\end{gathered}
$$

The amplitude response $A$ is the ratio between the amplitude of water level oscillations and that of earth tidal dilation strain, and the phase shift $\eta$ is the time lag of the water level oscillations relative to that of the imposed dilation strain. $x_{0}$ is the complex amplitude of water level fluctuation, and $h_{0}$ is the complex amplitude of pressure head fluctuation. $T$ is the transmissivity $\left(\mathrm{m}^{2} / \mathrm{s}\right), S_{s}$ is the specific storage $(1 / \mathrm{m}), S$ is the storage coefficient, $\operatorname{Ker}\left(\alpha_{w}\right)$ and $\operatorname{Kei}\left(\alpha_{w}\right)$ are the real and imaginary parts of zero-order Kelvin function, $r_{w}$ is the radius of the well $(\mathrm{m}), r_{c}$ is the inner radius of the casing $(\mathrm{m})$, and $\omega$ is the frequency of the tide $(\mathrm{rad} / \mathrm{s})$.

4.2.2. Vertical Flow Model. When the water head gradient is vertical, the well water level tidal response can be simulated by periodic loading applied at the surface of a half-space and finite layer $[19,25]$. The boundary condition at the water table is drained, and at the infinite depth, the boundary is undrained [26]. The pore pressure is related to the surface load, and its magnitude is the amplitude response $A$. Wang [25] presented an analytical solution to the water level tidal response under this condition. The amplitude response $A$ is given by

$$
A=\left|\frac{x_{0}}{h_{0}}\right|=\gamma \sigma_{0}\left[1-2 \exp \left(-\frac{z}{\delta}\right) \cos \frac{z}{\delta}+\exp \left(-\frac{2 z}{\delta}\right)\right]^{1 / 2}
$$

where

$$
\delta=\sqrt{\frac{2 D}{\omega}} .
$$




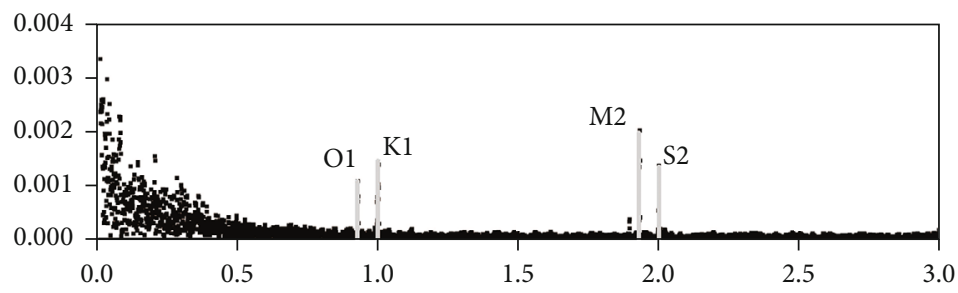

- J7
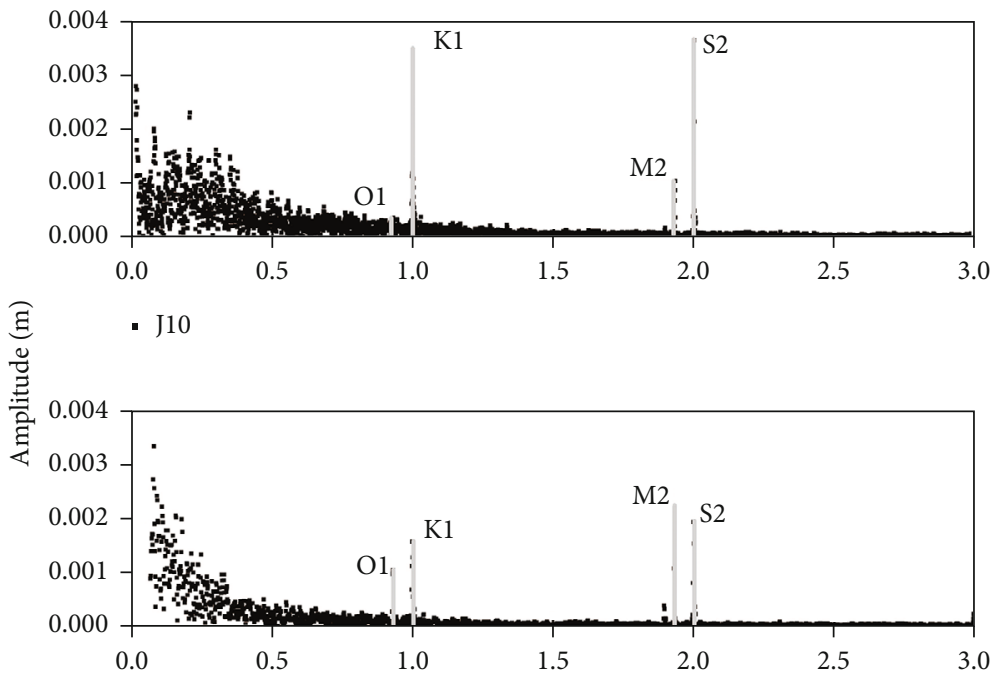

- J14

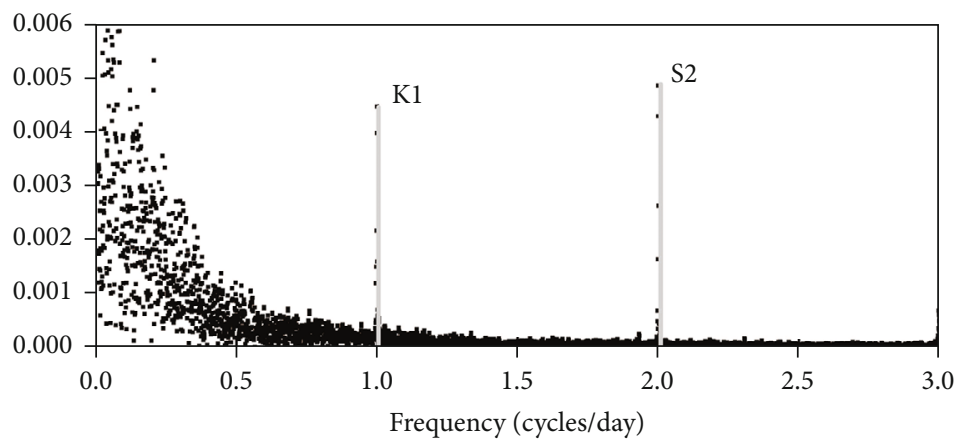

- Barometric

Figure 6: The amplitude spectrum of water level and barometric pressure data from September 2015 to September 2017. The vertical gray lines indicate the $\mathrm{K} 1, \mathrm{O} 1, \mathrm{M} 2$, and S2 tidal constituents.

The phase shift $\eta$ is given by

$$
\eta=\arg \left(\frac{x_{0}}{h_{0}}\right)=\tan ^{-1}\left\{\frac{\exp (-z / \delta) \sin (z / \delta)}{1-\exp (-z / \delta) \cos (z / \delta)}\right\}
$$

where $\gamma \sigma_{0}$ is the amplitude of pore pressure, $z$ is the depth from the water table, and $D$ is the hydraulic diffusivity which equals the division of transmissivity $T$ and storage coefficient $S$.

To get the values of $T$ and $S$ separately, we used a simplified method to determine the specific storage $S_{S}$ [17]. The specific storage can be defined as

$$
S_{S}=\rho g[(1-n) \alpha+n \beta]
$$

and the relation of water level to tidal dilation strain can be shown as

$$
x=\frac{\varepsilon_{v}}{\rho g[(1-n) \alpha+n \beta]},
$$

where $\rho$ is the fluid density $\left(\mathrm{kg} / \mathrm{m}^{3}\right), g$ is the acceleration of gravity $\left(\mathrm{m} / \mathrm{s}^{2}\right), n$ is the porosity of the aquifer, $\alpha$ is the compressibility of the rock $\left(\mathrm{MPa}^{-1}\right), \beta$ is the compressibility of the fluid $\left(\mathrm{MPa}^{-1}\right)$, and $\varepsilon_{v}$ is the aquifer dilation strain (volume strain). By combining equations (10) and (11), $S_{S}$ can be shown as 


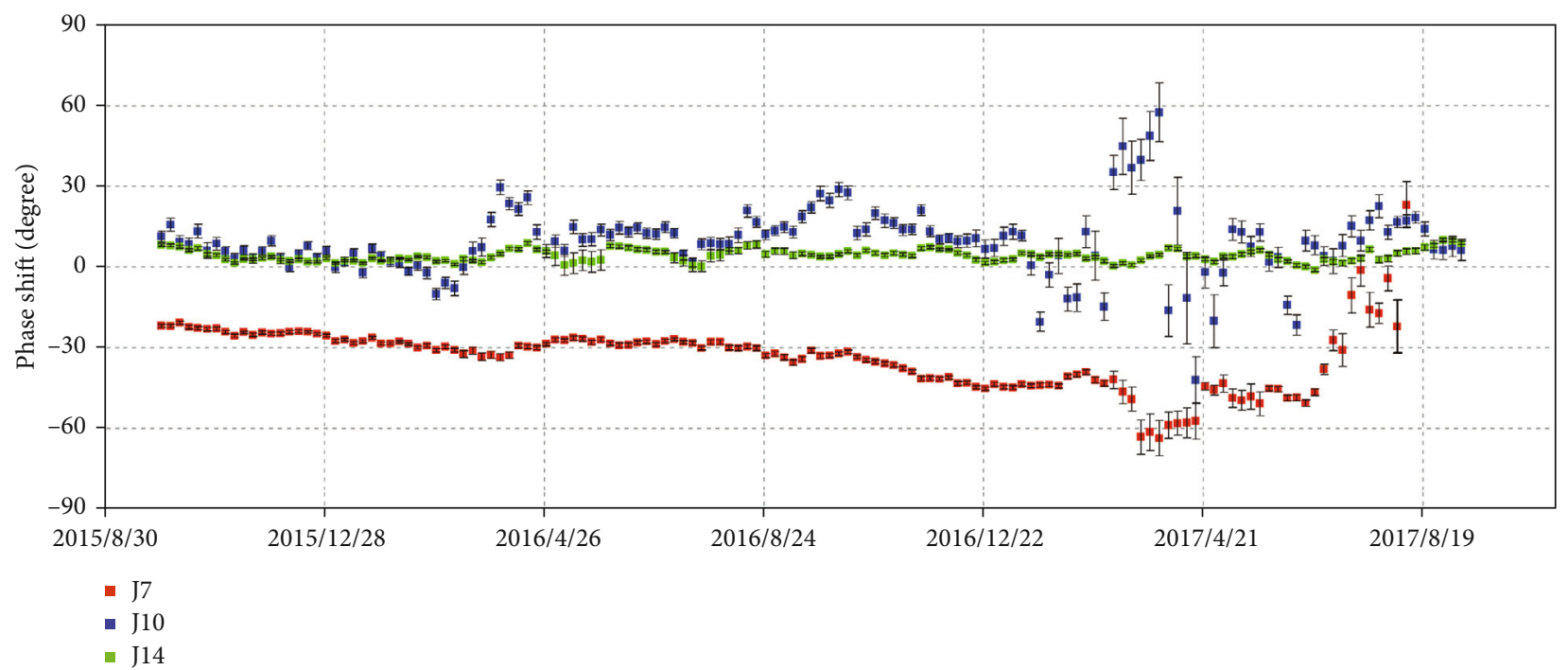

(a)

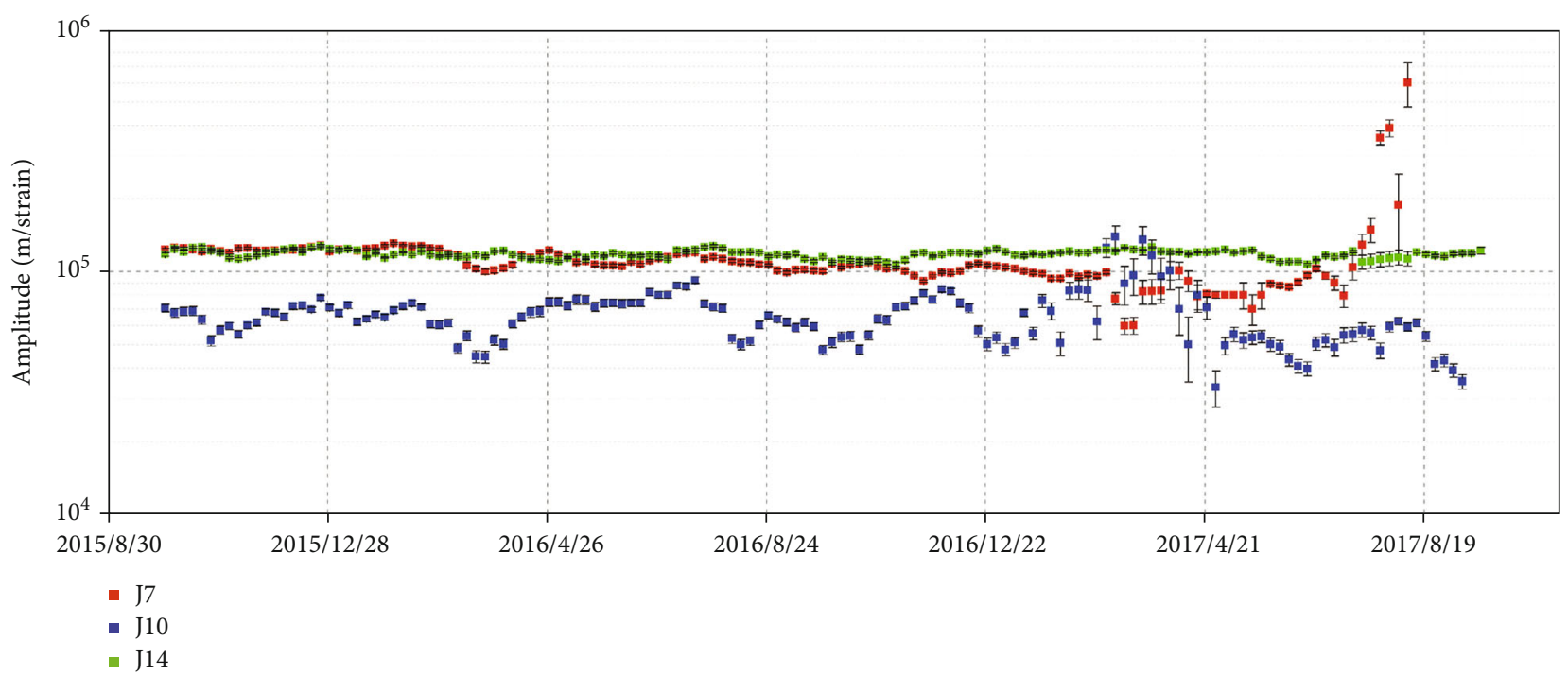

(b)

FIgURE 7: Phase shift (a) and amplitude response (b). The different colors show the results for different wells.

$$
S_{S}=\frac{\varepsilon_{v}}{x}
$$

If the barometric pressure effects are removed from the tidal analysis, the aquifer dilation strain $\varepsilon_{v}$ is equal to the tidal dilation strain $\varepsilon$. Thus, equation (12) can be rewritten as

$$
S_{S}=\frac{\varepsilon}{x}=\frac{1}{A}
$$

Therefore, storage coefficient $S$ can be obtained according to equations (6) and (13), and the corresponding transmissivity $T$ can be calculated by

$$
T=D S=D S_{s} d
$$

\section{Results}

5.1. Spectrum of Water Level. The results of the spectral analysis are shown in Figure 6. It can be seen that tidal constituents at $\mathrm{O} 1, \mathrm{~K} 1, \mathrm{~S} 2$, and M2 of all the wells are clear, which indicated a good response to tidal loading. The spectra of the barometric pressure, however, show only two clear constituents at K1 and S2, which means that the K1 and S2 constituents in water level are greatly affected by barometric pressure. Also, the $\mathrm{O} 1$ constituents in all wells are smaller than M2. Therefore, we focused on the tidal response at the frequency of M2, which has relatively large signal-to-noise ratios, and it is less affected by barometric loading.

5.2. Tidal Response and Hydrogeological Parameters. Figure 7 clearly shows that there are no obvious changes in phase and amplitude response of well water level at the J14 well; 


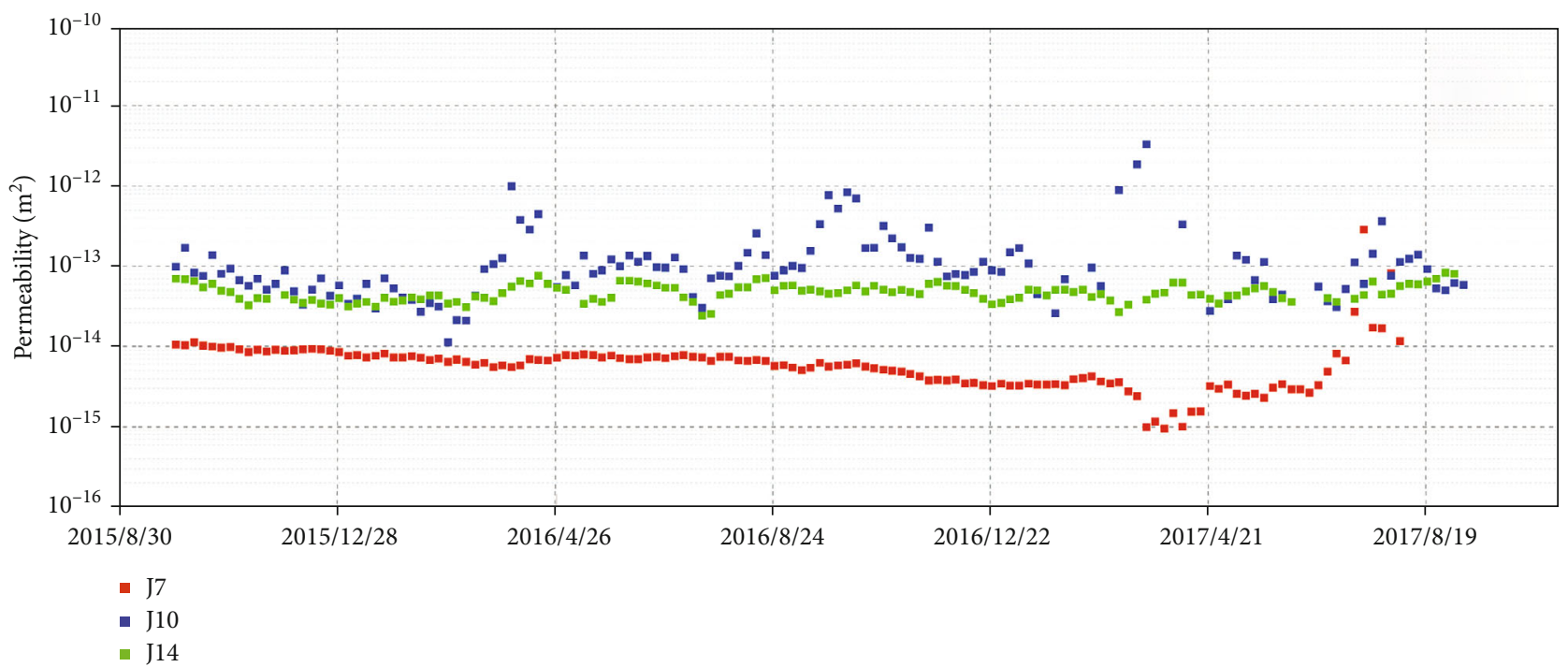

(a)

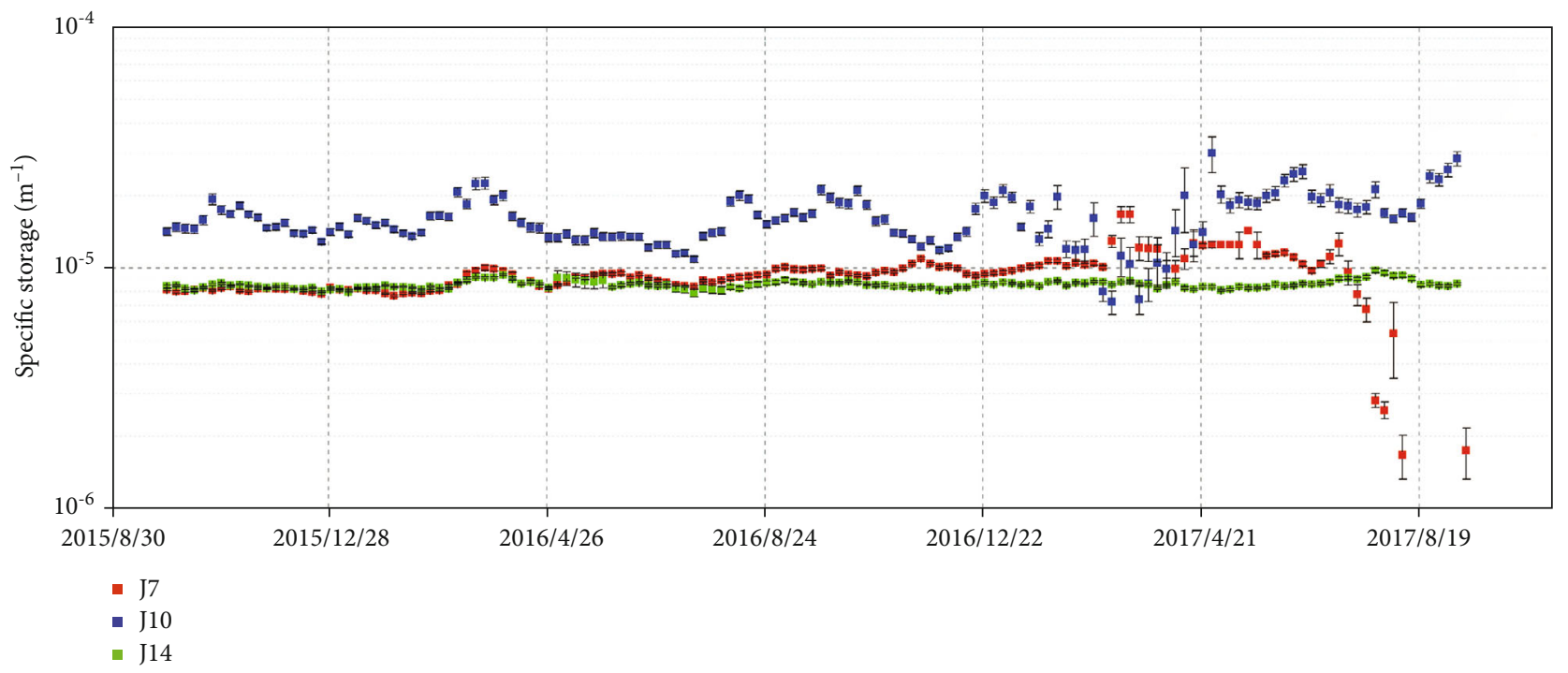

(b)

Figure 8: (a) Permeability and (b) specific storage. The different colors show the results for different wells.

however, the phase and amplitude response of $\mathrm{J} 7$ and $\mathrm{J} 10$ changed significantly when the longwall excavation zone approached each well. The phase shift of the J7 well decreased firstly and then increased during the mining. From the start of mining to June 2017, the phase shift of J7 declined gradually $\left(25^{\circ}\right)$. The phase shift of J7 started increasing as the coal face approached and eventually undermined the coal beneath the borehole, and the increment is $42^{\circ}$. The phase shift of J10 increased by $40^{\circ}$ during the times when the longwall coal face approached the borehole and recovered about two months later. Furthermore, the phase shift of the J7 well dropped 14 degrees in March 2017 and recovered after a month. We infer that the sudden drop of phase shift might be related to the two unexpected water level drops in the J7 well as mentioned before. At that time, the work face is still about 1400 meters away from the $\mathrm{J7}$ well. Though the amplitude changes are relatively insensitive compared with the phase shift changes
[20], the amplitude response in J7 and J10 shows a relatively good agreement with phase shift changes (Figure 7(b)).

Based on the measured phase and amplitude response, we use two models to calculate the transmissivity $(T)$ and storage coefficient $(S)$; the relationship between transmissivity $(T)$ and permeability $(k)$ is

$$
k=\frac{\mu}{\rho g d} T
$$

where $k$ is the permeability $\left(\mathrm{m}^{2}\right), \mu$ is the dynamic viscosity (Pa.s), $\rho$ is the density $\left(\mathrm{kg} / \mathrm{m}^{3}\right), g$ is the gravitational acceleration $\left(\mathrm{m} / \mathrm{s}^{2}\right)$, and $d$ is aquifer thickness $(\mathrm{m})$. The storage coefficient $(S)$ can be obtained by equation (6). The calculated permeability $k$ and storage coefficient of the formation surrounding these three wells are shown in Figure 8. The permeability of the J7 and J10 wells exhibited a similar trend to that 


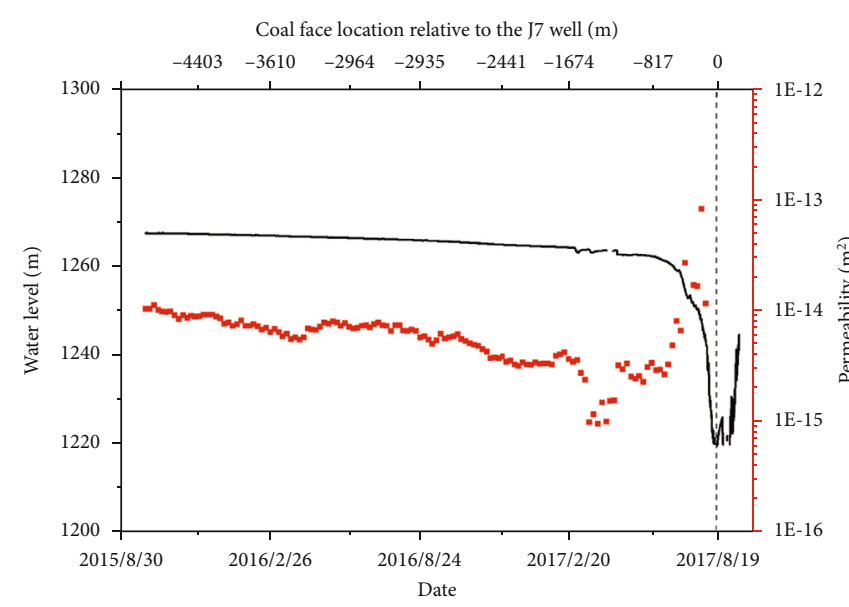

(a)

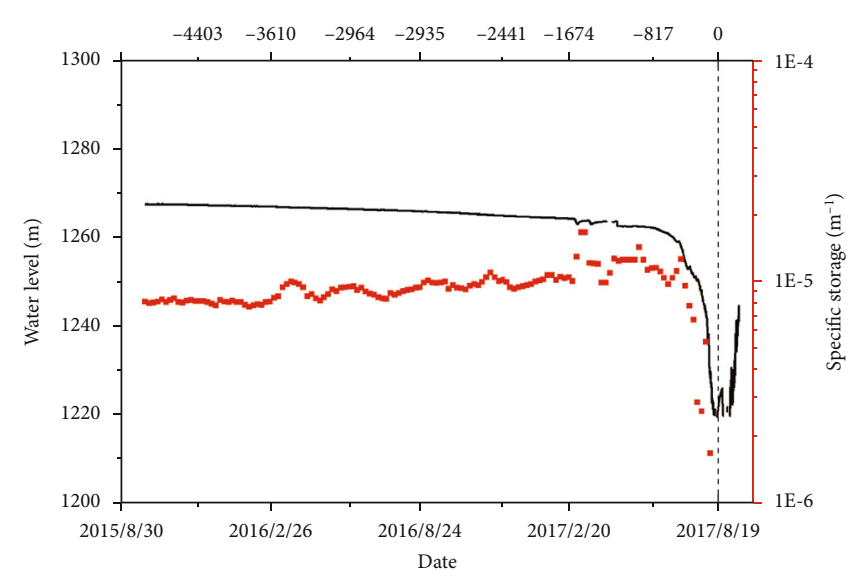

(b)

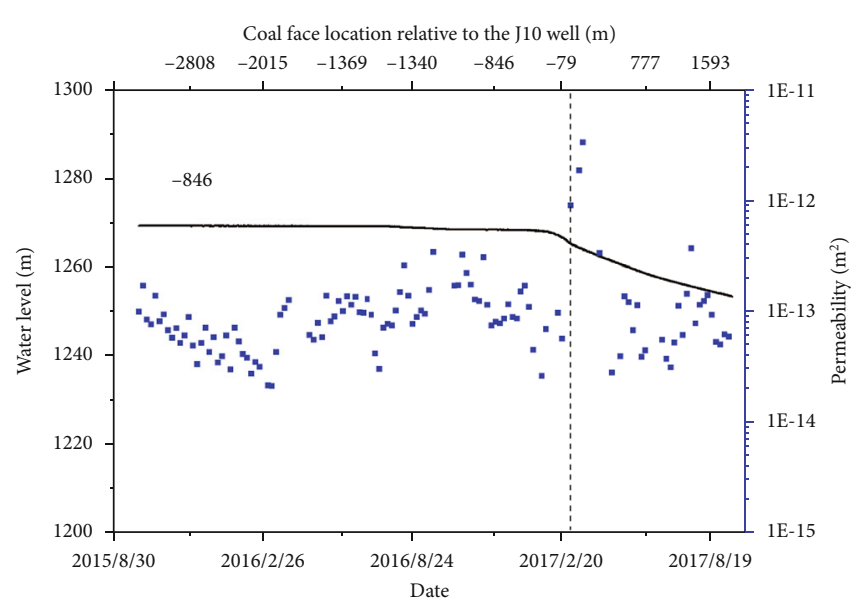

(c)

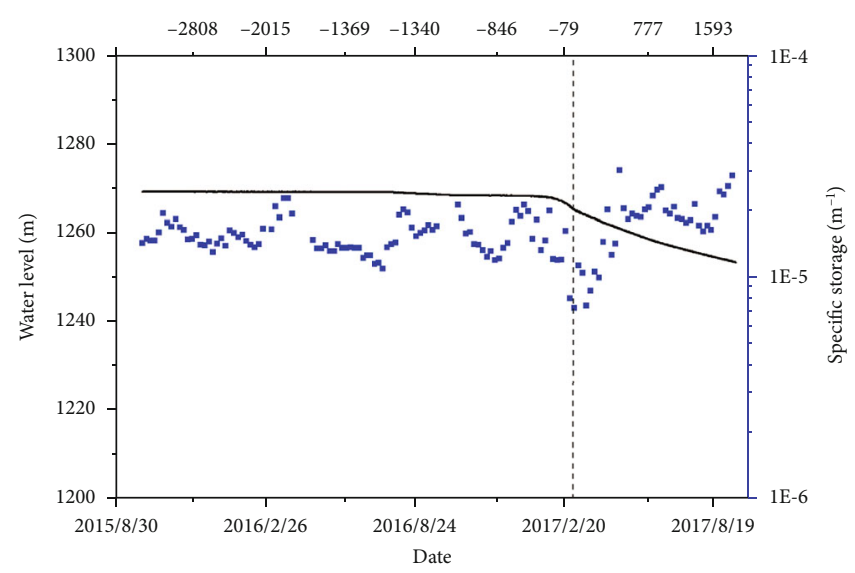

(d)

$$
\begin{aligned}
& \text { _ J7 water level } \\
& \text { - J7 specific storage }
\end{aligned}
$$

- J10 water level
- J10 specific storage

FIGURE 9: Variations of water level, permeability, and specific storage of J7 and J10 as a function of longwall coal face location relative to borehole location. Negative values represent a coal face location before it reaches the borehole location, where positive values represent the location of the coal face after undermining. The dash lines show the times when the longwall excavation zone is closest to the J10 and J7 wells, respectively.

of the phase shift. When the longwall excavation zone approached the wells, both the J7 and J10 permeability has increased by several to dozens of times.

\section{Discussion}

6.1. Aquifer Hydrogeological Parameter Changes during Mining. Figure 9 shows the variation in water level, permeability, and specific storage of $\mathrm{J} 7$ and $\mathrm{J} 10$ as a function of coal face location with respect to borehole location. The permeability of J7 and J10 declined gradually at first which was similar to the change in water level. In March 2017, the changes of permeability and specific storage of $\mathrm{J7}$ are related to the two abnormal water level fluctuations as mentioned before. The earlier aquifer hydrogeological parameter changes may be related to slow depressurization and dewatering [27]. It is worth noting that during this period, the values of the parameters in J10 are relatively variable compared with that of J7. This might be due to the strong effect of the barometric pressure in the J10 well (Figure 6).

As the water levels change rapidly, the permeability and specific storage of $\mathrm{J} 7$ started to change drastically when the coal face was approximately $300 \mathrm{~m}$ away from the $\mathrm{J} 7$ well and eventually undermined the well. During this period, the value of permeability increased from $4.81 \times 10^{-15} \mathrm{~m}^{2}$ to $1.15 \times 10^{-14} \mathrm{~m}^{2}$ (Figure 9(a)), and the value of specific storage decreased from $1.04 \times 10^{-5} \mathrm{~m}^{-1}$ to $5.32 \times 10^{-6} \mathrm{~m}^{-1}$. The variation in the values of J10 was similar to J7. An obvious increase in permeability was observed to be from $5.57 \times 10^{-14} \mathrm{~m}^{2}$ to $3.27 \times 10^{-12} \mathrm{~m}^{2}$ when the coal face was about $80 \mathrm{~m}$ away from $\mathrm{J} 10$ (Figure $9(\mathrm{c})$ ). When the coal face was about $300 \mathrm{~m}$ away from the J10 well, the specific storage of J10 started to decline until the coal face eventually undermined the well and subsequently recovered to its previous value. 
These results may be explained by the fact that the permeability is controlled by mining-induced stress $[8,11]$. The tensile stress in front of the work face possibly creates new fractures, which could increase the permeability of the aquifer around the wells. With the advance of the coal face, the tensile stress converts to compressive stress after the coal face undermined the well $[28,29]$. In this case, the permeability of the aquifer around the wells will decrease due to formation compression and fracture closure.

The decrease of specific storage is due to the reduction of pore water pressure and porosity induced by drainage and aquifer compression. It is worth mentioning that the specific storage of J10 recovered to its previous level in the postclosure period. The increase of the specific storage of J10 after the coal face passed may be interpreted by aquifer rebound [30].

6.2. Water Level Changes Associated with Mining. From the start of mining, the water level of J7 and J10 is relatively stable or gradually decreased, which can be attributed to slow depressurization and dewatering of other mining faces elsewhere in the coalfield. Rapid declines in water levels occurred when the longwall excavation zone approached J7 and J10 wells, and the water level of J7 drops significantly faster than that of J10. The sharp water level drops in J7 and J10 are likely due to dewatering via the new fracture created by fracturing and dilation of joints [31].

Combined with the variation in water level and aquifer hydrogeological parameters, the aquifer deformation around J7 and J10 wells might be elastic during mining. For a deep confined aquifer, the hydraulic head recovery may not be related to recharge [32], and the recovery of the J7 water level might be related to the water released by partial closure of fractures during the formation compression [30, 32]. It is interesting to note that no recovery was observed in the water level in the J10 well while the hydrogeological parameters of J10 recovered to their previous level after the coal face passed as mentioned before. Therefore, it can be inferred that the continuous decline of the water level in the J10 well is probably due to the continuous leakage from the aquifer around the J10 well to other connected aquifers.

6.3. Uncertainty and Future Perspectives. There are some uncertainties of the estimated results. Due to the lack of field monitoring strain data, we can only determine aquifer parameters based on the theoretical solid tides, which may lead to error in the estimations. In the period of the drastic change of the well water level, the standard deviations of calculated phase and amplitude are relatively large, which leads to the corresponding uncertainty of estimated permeability and specific storage. Besides, we were unable to make a complete evaluation of the aquifer parameter changes of the J7 well due to the missing subsequent recovery water level data of the well. Nevertheless, this study showed the primary characteristics of the aquifer parameter changes under coal mining and demonstrated that the tidal effects of the well water level can be effectively used to investigate such changes. It is worth noting that mining-induced changes in hydrogeological parameters of overburden aquifer may be related to site- specific structures and operations of coal mines. It is expected that more research would be conducted in the future to improve the accuracy of parameter estimations and to further understand the changes in aquifer structure and properties and hydrological circle caused by mining.

\section{Conclusion}

In this paper, we use the method of the tidal response of well water level to explore the changes in hydrogeological parameters of the overburden aquifer in the mining area. Based on the long-term water level monitoring data, two analytical models were used to determine the temporal changes of hydrogeological parameters under mining disturbance. The main conclusions can be drawn as follows:

(1) The permeability of aquifer can increase by several to dozens of times when the longwall excavation zone approached the monitoring wells; the response distances of aquifer deformation to mining can be up to $300 \mathrm{~m}$

(2) During mining, the drawdown of water level in wells is likely due to dewatering via the new fracture created by mining; the well water level and hydrogeological parameters may be recovered after the work face passed, possibly due to the rebound effects of aquifer

(3) The changes in well water level and hydrogeological parameters in different monitoring sites (wells) showed different characteristics, which may be related to the well and aquifer structures as well as the positions of the monitoring wells relative to the coal face

The results of this study could enhance our understanding of the hydrogeological parameter changes in the overburden aquifers and could have implications for groundwater protection and safety of mining in coal mine areas.

\section{Data Availability}

The data supporting the results of this article are included within the article and can be obtained from the corresponding author (wanggc@pku.edu.cn) upon request.

\section{Conflicts of Interest}

The authors declare no conflicts of interest.

\section{Acknowledgments}

This work is supported by the National Natural Science Foundation of China (41272269). We thank Dr. Liang Guo and Mr. Ziguan Wang for valuable discussions and assistance in field sampling.

\section{References}

[1] B. Zhu, Q. Wu, J. Yang, and T. Cui, "Study of pore pressure change during mining and its application on water inrush 
prevention: a numerical simulation case in Zhaogezhuang coalmine, China," Environmental Earth Sciences, vol. 71, no. 5, pp. 2115-2132, 2014.

[2] D. P. Adhikary and H. Guo, "Modelling of longwall mininginduced strata permeability change," Rock Mechanics and Rock Engineering, vol. 48, no. 1, pp. 345-359, 2015.

[3] R. Fawcett, S. Hibberd, and R. Singh, "An appraisal of mathematical models to predict water inflows into underground coal workings," International Journal of Mine Water, vol. 3, no. 2, pp. 33-54, 1984.

[4] B. A. Poulsen, D. Adhikary, and H. Guo, "Simulating mininginduced strata permeability changes," Engineering Geology, vol. 237, pp. 208-216, 2018.

[5] J. Zhang and B. Shen, "Coal mining under aquifers in China: a case study," International Journal of Rock Mechanics and Mining Sciences, vol. 41, no. 4, pp. 629-639, 2004.

[6] K. Miyakawa, T. Nohara, T. Tokiwa, and M. Yamazaki, "Seven-year history of vertical hydraulic diffusivity related to excavation around an underground facility," International Journal of Rock Mechanics and Mining Sciences, vol. 70, pp. 332-342, 2014.

[7] S. J. Schatzel, C. Ö. Karacan, H. Dougherty, and G. V. R. Goodman, "An analysis of reservoir conditions and responses in longwall panel overburden during mining and its effect on gob gas well performance," Engineering Geology, vol. 127, pp. 65-74, 2012.

[8] J. Liu and D. Elsworth, "Three-dimensional effects of hydraulic conductivity enhancement and desaturation around mined panels," International Journal of Rock Mechanics and Mining Sciences, vol. 34, no. 8, pp. 1139-1152, 1997.

[9] W. X. Wang, W. H. Sui, B. Faybishenko, and W. T. Stringfellow, "Permeability variations within mining-induced fractured rock mass and its influence on groundwater inrush," Environmental Earth Sciences, vol. 75, no. 4, p. 326, 2016.

[10] C. Booth, "The effects of longwall coal mining on overlying aquifers," Geological Society, London, Special Publications, vol. 198, no. 1, pp. 17-45, 2002.

[11] C. Özgen Karacan and G. Goodman, "Hydraulic conductivity changes and influencing factors in longwall overburden determined by slug tests in gob gas ventholes," International Journal of Rock Mechanics and Mining Sciences, vol. 46, no. 7, pp. 1162-1174, 2009.

[12] Z. Huang, Z. Jiang, S. Zhu, X. Wu, L. Yang, and Y. Guan, "Influence of structure and water pressure on the hydraulic conductivity of the rock mass around underground excavations," Engineering Geology, vol. 202, pp. 74-84, 2016.

[13] H. H. Cooper, J. D. Bredehoeft, I. S. Papadopulos, and R. R. Bennett, "The response of well-aquifer systems to seismic waves," Journal of Geophysical Research, vol. 70, no. 16, pp. 3915-3926, 1965.

[14] J. D. Bredehoeft, "Response of well-aquifer systems to Earth tides," Journal of Geophysical Research, vol. 72, no. 12, pp. 3075-3087, 1967.

[15] R. I. Acworth and T. Brain, "Calculation of barometric efficiency in shallow piezometers using water levels, atmospheric and earth tide data," Hydrogeology Journal, vol. 16, no. 8, pp. 1469-1481, 2008.

[16] T. J. Burbey, "Fracture characterization using Earth tide analysis," Journal of Hydrology, vol. 380, no. 3-4, pp. 237-246, 2010.
[17] G. H. Rhoads and E. S. Robinson, "Determination of aquifer parameters from well tides," Journal of Geophysical Research, vol. 84, no. B11, p. 6071, 1979.

[18] P. A. Hsieh, J. D. Bredehoeft, and J. M. Farr, "Determination of aquifer transmissivity from Earth tide analysis," Water Resources Research, vol. 23, no. 10, pp. 1824-1832, 1987.

[19] E. Roeloffs, "Poroelastic techniques in the study of earthquakerelated hydrologic phenomena," in Advances in Geophysics Volume 37, no. 37pp. 135-195, Elsevier, 1996.

[20] J. E. Elkhoury, E. E. Brodsky, and D. C. Agnew, "Seismic waves increase permeability," Nature, vol. 441, no. 7097, pp. 11351138, 2006.

[21] L. Xue, H. B. Li, E. E. Brodsky et al., "Continuous permeability measurements record healing inside the Wenchuan earthquake fault zone," Science, vol. 340, no. 6140, pp. 1555-1559, 2013.

[22] G. Lai, H. Ge, L. Xue, E. E. Brodsky, F. Huang, and W. Wang, "Tidal response variation and recovery following the Wenchuan earthquake from water level data of multiple wells in the nearfield," Tectonophysics, vol. 619-620, pp. 115-122, 2014.

[23] Z. Shi, G. Wang, C.-y. Wang, M. Manga, and C. Liu, "Comparison of hydrological responses to the Wenchuan and Lushan earthquakes," Earth and Planetary Science Letters, vol. 391, pp. 193-200, 2014.

[24] X. Huang, G. Wang, X. Liang, L. Cui, L. Ma, and Q. Xu, "Hydrochemical and stable isotope $(\delta \mathrm{D}$ and $\delta 18 \mathrm{O})$ characteristics of groundwater and hydrogeochemical processes in the Ningtiaota Coalfield, Northwest China," Mine Water and the Environment, vol. 37, no. 1, pp. 119-136, 2018.

[25] H. Wang, Theory of Linear Poroelasticity, Princeton Univ. Press, Princeton, NJ, 2000.

[26] L. Xue, E. E. Brodsky, J. Erskine, P. M. Fulton, and R. Carter, "A permeability and compliance contrast measured hydrogeologically on the San Andreas Fault," Geochemistry, Geophysics, Geosystems, vol. 17, no. 3, pp. 858-871, 2016.

[27] P. Hsieh, "Deformation-induced changes in hydraulic head during ground-water withdrawal," Ground Water, vol. 34, no. 6, pp. 1082-1089, 1996.

[28] S. G. Wang, D. Elsworth, and J. S. Liu, "Permeability evolution during progressive deformation of intact coal and implications for instability in underground coal seams," International Journal of Rock Mechanics and Mining Sciences, vol. 58, pp. 34-45, 2013.

[29] Y. Lu, L. Cheng, Z. Ge, B. Xia, Q. Li, and J. Chen, “Analysis on the initial cracking parameters of cross-measure hydraulic fracture in underground coal mines," Energies, vol. 8, no. 7, pp. 6977-6994, 2015.

[30] K. David, W. A. Timms, S. L. Barbour, and R. Mitra, “Tracking changes in the specific storage of overburden rock during longwall coal mining," Journal of Hydrology, vol. 553, pp. 304-320, 2017.

[31] C. J. Booth and E. D. Spande, "Potentiometric and aquifer property changes above subsiding longwall mine panels, Illinois Basin Coalfield," Groundwater, vol. 30, no. 3, pp. 362368, 1992.

[32] C. J. Booth, "Confined-unconfined changes above longwall coal mining due to increases in fracture porosity," Environmental and Engineering Geoscience, vol. 13, no. 4, pp. 355367, 2007. 